\title{
Long-term outcomes of active surveillance for clinically localized prostate cancer in a community-based setting: results from a prospective non-interventional study
}

\author{
Jan Herden ${ }^{1,2}$ (D) Andreas Schwarte ${ }^{3,4} \cdot$ Thorsten Werner $^{5} \cdot$ Uwe Behrendt $^{6} \cdot$ Axel Heidenreich $^{1} \cdot$ Lothar Weissbach $^{7}$
}

Received: 23 June 2020 / Accepted: 21 September 2020 / Published online: 30 September 2020

(c) The Author(s) 2020

\begin{abstract}
Purpose To report on long-term outcomes of patients treated with active surveillance (AS) for localized prostate cancer $(\mathrm{PCa})$ in the daily routine setting.

Methods HAROW (2008-2013) was a non-interventional, health service research study about the management of localized $\mathrm{PCa}$ in the community setting, with $86 \%$ of the study centers being office-based urologists. A follow-up examination of all patients who opted for AS as primary treatment was carried out. Overall, cancer-specific, and metastasis-free survival, as well as discontinuation rates, were determined.

Results Of 329 patients, $62.9 \%$ had very-low- and $21.3 \%$ low-risk tumours. The median follow-up was 7.7 years (IQR 4.7-9.1). Twenty-eight patients (8.5\%) died unrelated to PCa, of whom 19 were under AS or watchful waiting (WW). Additionally, seven patients (2.1\%) developed metastasis. The estimated 10-year overall and metastasis-free survival was $86 \%$ (95\% CI 81.7-90.3) and 97\% (95\% CI 94.6-99.3), respectively. One hundred eighty-seven patients (56.8\%) discontinued AS changing to invasive treatment: 104 radical prostatectomies (RP), 55 radiotherapies (RT), and 28 hormonal treatments (HT). Another 50 patients switched to WW. Finally, 37.4\% remained alive without invasive therapy (22.2\% AS and $15.2 \%$ WW). Intervention-free survival differed between the risk groups: $47.8 \%$ in the very-low-, $33.8 \%$ in the low- and $34.6 \%$ in the intermediate-/high-risk-group ( $p=0.008)$. On multivariable analysis, PSA-density $\geq 0.2 \mathrm{ng} / \mathrm{ml}^{2}$ was significantly predictive for receiving invasive treatment (HR $2.55 ; p=0.001)$.

Conclusion Even in routine care, AS can be considered a safe treatment option. Our results might encourage office-based urologists regarding the implementation of AS and to counteract possible concerns against this treatment option.
\end{abstract}

Keywords HAROW study · Active surveillance $\cdot$ Conservative management $\cdot$ Health service research · Outcomes research · Routine care

Electronic supplementary material The online version of this article (https://doi.org/10.1007/s00345-020-03471-x) contains supplementary material, which is available to authorized users.

Jan Herden

jan.herden@uk-koeln.de

1 University of Cologne, Faculty of Medicine and University Hospital Cologne, Department of Urology, Uro-Oncology, Robot-Assisted and Reconstructive Urology, Cologne, Germany

2 PAN Clinic, Urological Practice, Cologne, Germany

\section{Introduction}

Active surveillance (AS) is a non-invasive treatment strategy for patients with well-differentiated, localized prostate cancer (PCa). In contrast to watchful waiting (WW) being a palliative option for patients with reduced life expectancy,

3 Urological Practice Borken, Borken, Germany

4 Department of Urology, St. Agnes Hospital Bocholt, Bocholt, Germany

5 Urological Practice Herzberg, Herzberg Am Harz, Germany

6 Urological Practice Wittenbergplatz, Berlin, Germany

7 Health Research for Men GmbH, Berlin, Germany 
AS implies curative intention. Prostate-specific antigen (PSA) assessment, digital rectal examination (DRE), and re-biopsies are performed frequently to switch to invasive treatment when signs of progression occur $[1,2]$.

Prospective clinical long-term AS studies have confirmed a 10 -year cancer-specific-survival of $>98 \%$, which is comparable to that of an immediate invasive treatment [3-8].

Noteworthy, most of these studies are clinical trials from large academic centers with stringent inclusion and exclusion criteria. Since in "real life" AS is mainly applied by office-based urologists, the question arises whether this leads to similarly promising results in daily routine care.

The HAROW study (2008-2013) is a prospective, multicenter, health service research study with the aim of investigating the treatment of localized PCa in the community setting in Germany [9]. The name represents the five possible treatment options: hormonal treatment (HT), AS, radiotherapy (RT), radical prostatectomy $(\mathrm{OP}=\mathrm{RP})$, and $\mathrm{WW}$. Because it was conceived as a non-interventional observational study, no specifications were given regarding the choice of treatment or how it was carried out. The AS group was of particular interest because at the time of recruitment this strategy was relatively unknown and not widely used [10].

We herein report on the long-term outcomes of the AS cohort with up to 11 years of follow-up, including survival and metastatic outcomes, as well as discontinuation rates and risk factors for deferred invasive treatment.

\section{Patients and methods}

\section{HAROW study}

From July 2008-July 2013 patients with newly diagnosed localized $(\leq \mathrm{T} 2 \mathrm{c})$ PCa were prospectively enrolled by 259 study centers, $86 \%$ of which were office-based urologists. Half of them $(n=131)$ recruited patients in AS. Although at that time AS was already considered in the guidelines of the European Association of Urology (EAU) [11], it was still a new and largely non-accepted treatment strategy among German urologists. Because of the non-interventional character of the study, only recommendations regarding inclusion, follow-up, and discontinuation of AS were given corresponding to those available in the literature [12] and the European PRIAS study (Prostate Cancer Research International Active Surveillance), the then-largest published prospective trial of AS [13]. Inclusion criteria for AS were T-category $\leq \mathrm{cT} 2 \mathrm{c}, \mathrm{PSA} \leq 10 \mathrm{ng} / \mathrm{ml}$, Gleason grade group 1 , PSA-density $\leq 0.2 \mathrm{ng} / \mathrm{ml}^{2}$ and $\leq 2$ positive biopsies. The recommended follow-up procedure included DRE, PSA, and PSA doubling time (PSA-DT) every 3 months in the first 2 years, and every 6 months thereafter. Re-biopsy was recommended after 1 year, and then every 3 years. In case of histological evidence of progressive disease, increasing PSA levels with PSA-DT $<3$ years, or clinical signs of progression on DRE discontinuation of AS was recommended, alternatively on patient's request. Multiparametric magnetic resonance imaging (mpMRI) of the prostate was neither used nor recommended as it was not available at the time of recruitment. Data of recruitment, diagnostics, and course of disease in the total cohort for the study period with a median observation period of 28.4 months have been published elsewhere $[9,10,14]$.

\section{Follow-up of the AS group}

A follow-up survey of all AS patients including those who had switched to another form of treatment was carried out until August 2019. Questionnaires were sent to the patients by mail. All non-responders were contacted again and interviewed by telephone. In the case of missing response or lacking information on the course of the disease including the cause of death, treating study physicians were contacted. The following parameters were collected: Overall, cancerspecific, metastasis-free, and intervention-free survival, reasons for discontinuation of AS, and type of deferred treatment.

\section{Statistical analysis}

Data were analyzed using IBM's statistical program SPSS, version 22. Metric variables were evaluated by means of univariate ANOVA, and categorical variables analyzed using the chi-squared test or Fisher's-exact test. Kaplan-Meier method and log-rank test were used to analyze overall, metastasis-free, and intervention-free survival. We used logistic regression as a multivariate analysis to determine independent factors influencing the target variable "receiving interventional treatment". The significance level was set at $5 \%$ for all calculations.

\section{Results}

Of 2957 patients enrolled, 468 (15.8\%) chose AS. During the course of the HAROW-study and follow-up period reasons for drop-out included: consent withdrawn (5.1\%), lost to follow-up (20.7\%), and other reasons, e.g. change of residence, physician abandoned the practice, etc. (3.8\%). Finally, data from 329 patients were available for evaluation (Fig. 1).

Patient characteristics at baseline are presented in Table 1. Two hundred and seven (62.9\%) patients accounted for the very-low-, 70 (21.3\%) for the low-, and 52 (15.8\%) for the intermediate- or high-risk- group, respectively, according 


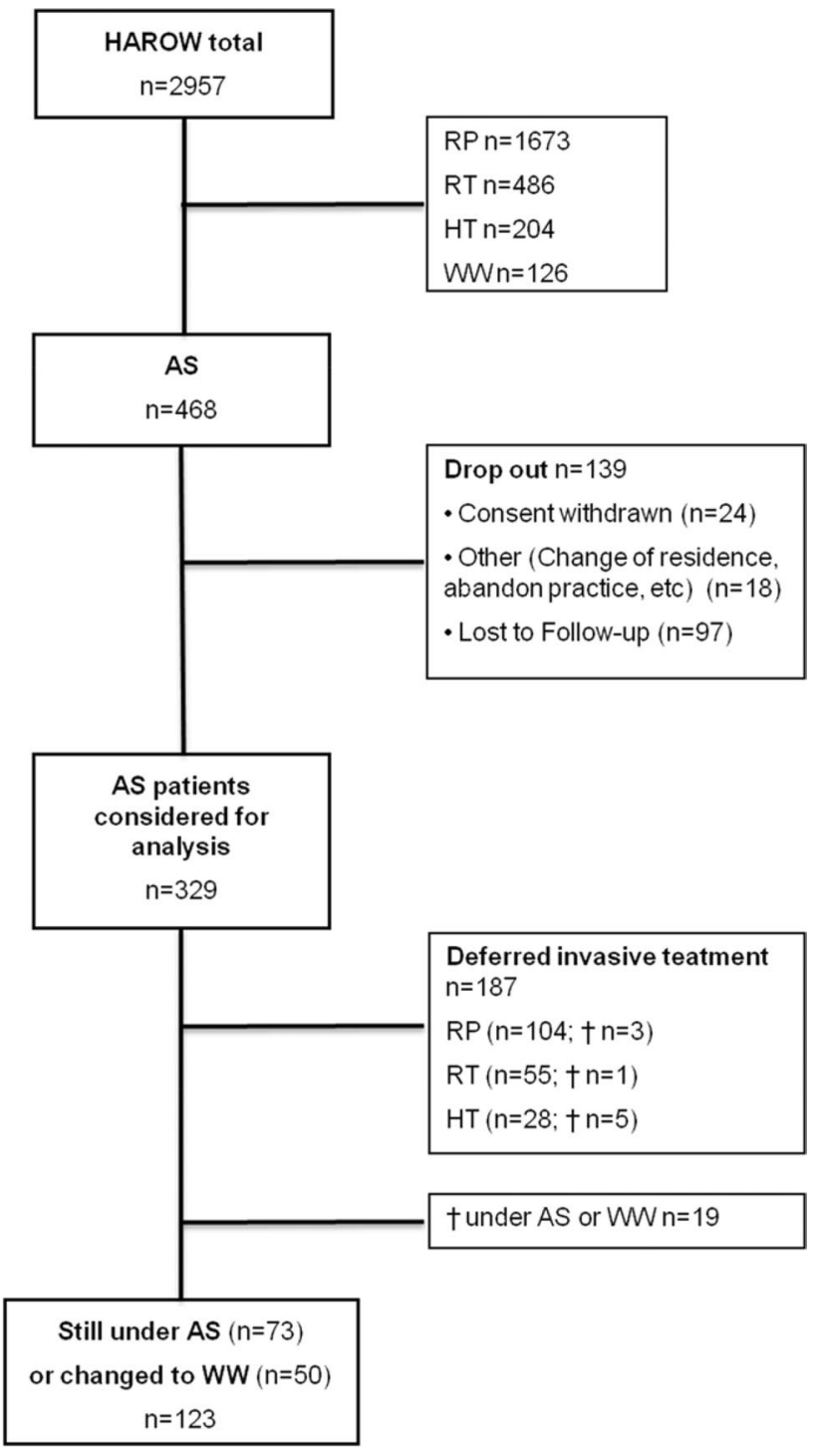

Fig. 1 Flow chart of the HAROW study and outcome of the active surveillance (AS) patients at the time of the last follow-up. $R P$ radical prostatectomy, $R T$ radiotherapy, $H T$ hormone treatment, $W W$ watchful waiting. ${ }^{\dagger}$ Death

to the National Comprehensive Cancer Network (NCCN) guidelines [2].

Median follow-up was 7.7 years (interquartilerange $=$ IQR 4.7-9.1, Min-Max 0.1-11.0). In this period, 28 patients $(8.5 \%)$ died at a median age of 74 years (IQR 72-78) after a median follow-up of 4.1 years (IQR 2.3-6.3), of which 19 were still under AS or WW. No PCa-specific cause of death could be detected. The main causes of death were other malignancies $(36 \%)$ and cardiovascular diseases (25\%) (Supplementary Table 1). Seven patients (2.1\%) developed metastasis after a median of 5.4 years (IQR 2.4-6.8), including five with very-low and two with intermediate-risk tumors (Supplementary Table 2). The
Kaplan-Meier estimated 10-year overall and metastasisfree survival was $86 \%$ (95\% CI 81.7-90.3) and 97\% (95\% CI 94.6-99.3), respectively (Fig. 2a + b).

A total of 187 patients (56.8\%) discontinued AS in favor of invasive treatment: 104 chose RP, 55 RT, and 28 HT. The main reasons for discontinuation were biopsy-upgrade and PSA-elevation in the RP-group (40.4\% and 33.7\%) and the RT-group (29.1\% each), and PSA-elevation and physician's advice (35.7\% and 19.7\%) in the HT-group (Supplementary Fig. 1). Additionally, 50 patients switched from AS to WW and maintained a non-invasive approach. These patients were older and had a lower baseline PSA and PSA-density compared to patients who remained on AS or switched to invasive treatment. No differences were seen regarding comorbidities (CCI) at baseline or among the distribution to the risk-groups (Table 1).

The median time to change to RP (33.0 months) and RT (38.5 months) was significantly shorter than to HT (59.1 months) and WW (70.1 months, $p<0.001)$.

Within the study period (2008-2013, mFU 28.5 months) information about follow-up examinations (re-biopsy and repeat PSA tests) as well as histology after deferred RP was stated: $71 \%$ had $\geq 4$ PSA measurements and $55 \%$ had at least one re-biopsy. Histological results from RP specimen were available from 65 patients. Locally advanced disease ( $\geq$ pT3) was seen in $8 / 65(12.3 \%)$ and Gleason grade group $\geq 3$ in $13 / 65(20.0 \%)$, with no significant differences among the risk-groups ( $p=0.6$ and $p=0.22$; Table 2$)$.

At the end of the observation period, 123 patients (37.4\%) were alive without an invasive therapy, including 73 (22.2\%) AS- and 50 (15.2\%) WW-patients (Fig. 1). However, intervention-free-survival differed between the risk groups: $47.8 \%$ for the very-low-, $33.8 \%$ for the low-and $34.6 \%$ for the intermediate-/high-risk group $(\mathrm{p}=0.008)($ Fig. 2c). In multivariable analysis, only PSA-density $\geq 0.2 \mathrm{ng} / \mathrm{ml}^{2}$ was significantly predictive for receiving an invasive treatment (HR 2.55; $p=0.001$ ) (Table 3).

\section{Discussion}

In the HAROW-study we evaluated the outcomes of patients with localized PCa under AS in the routine-care setting. A distinctiveness of the study is the design as a health-serviceresearch study. Other than most single-center AS-studies from academic or tertiary-care centers, HAROW aims to represent a "real-world"-situation with the inclusion of mainly office-based urologists across Germany. This is intended to increase the generalizability of the results since in routine-care office-based urologists in particular are at the forefront in managing AS. In addition to diagnosis and advice on management options of localized PCa, they are 
Table 1 Patient characteristics at baseline

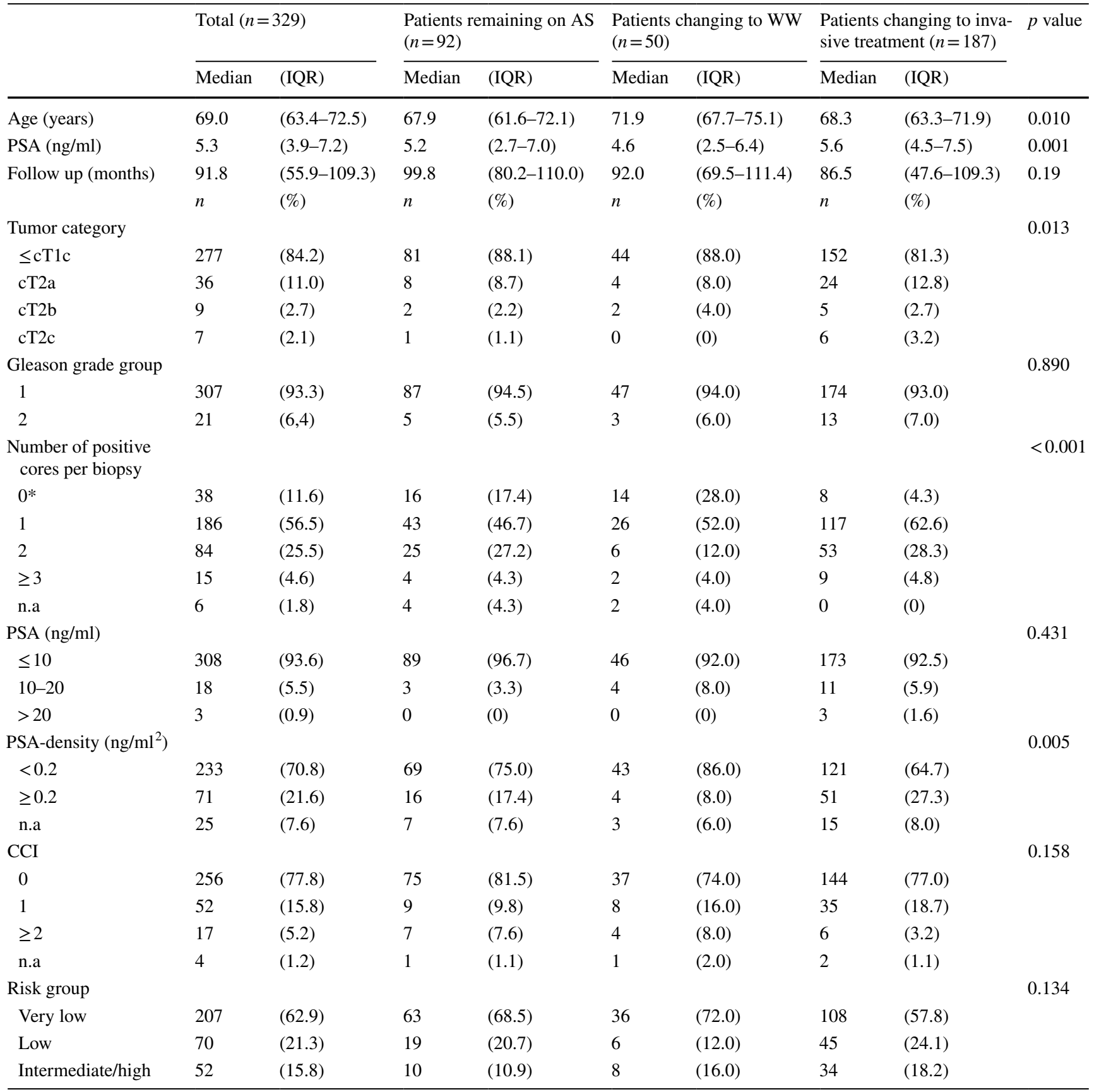

PSA prostate-specific antigen, n.a. not available

*Patients with no positive biopsies were diagnosed as incidental prostate cancer diagnosed by transurethral resection of the prostate

responsible for an essential part of the treatment and followup of AS-patients.

Short term outcomes of the AS cohort within the studyperiod (2008-2013, mFU 28.5 months) have already been published. It could be demonstrated that AS recommendations were largely respected. AS-patients who were contrarily admitted to these recommendations included $12.8 \%$ with intermediate- and 3\% with high-risk tumors, only
$2.1 \%$ had a PSA $>20 \mathrm{ng} / \mathrm{ml}$, and no Gleason-grade-group 3 were assigned to AS [10].

We now present the long-term outcomes which confirm AS as a safe treatment option also in the routine-care, since no PCa-specific death was observed and only $2.1 \%$ of the patients developed metastasis. On the other hand, our results indicate that with time, only $22 \%$ adhered to 

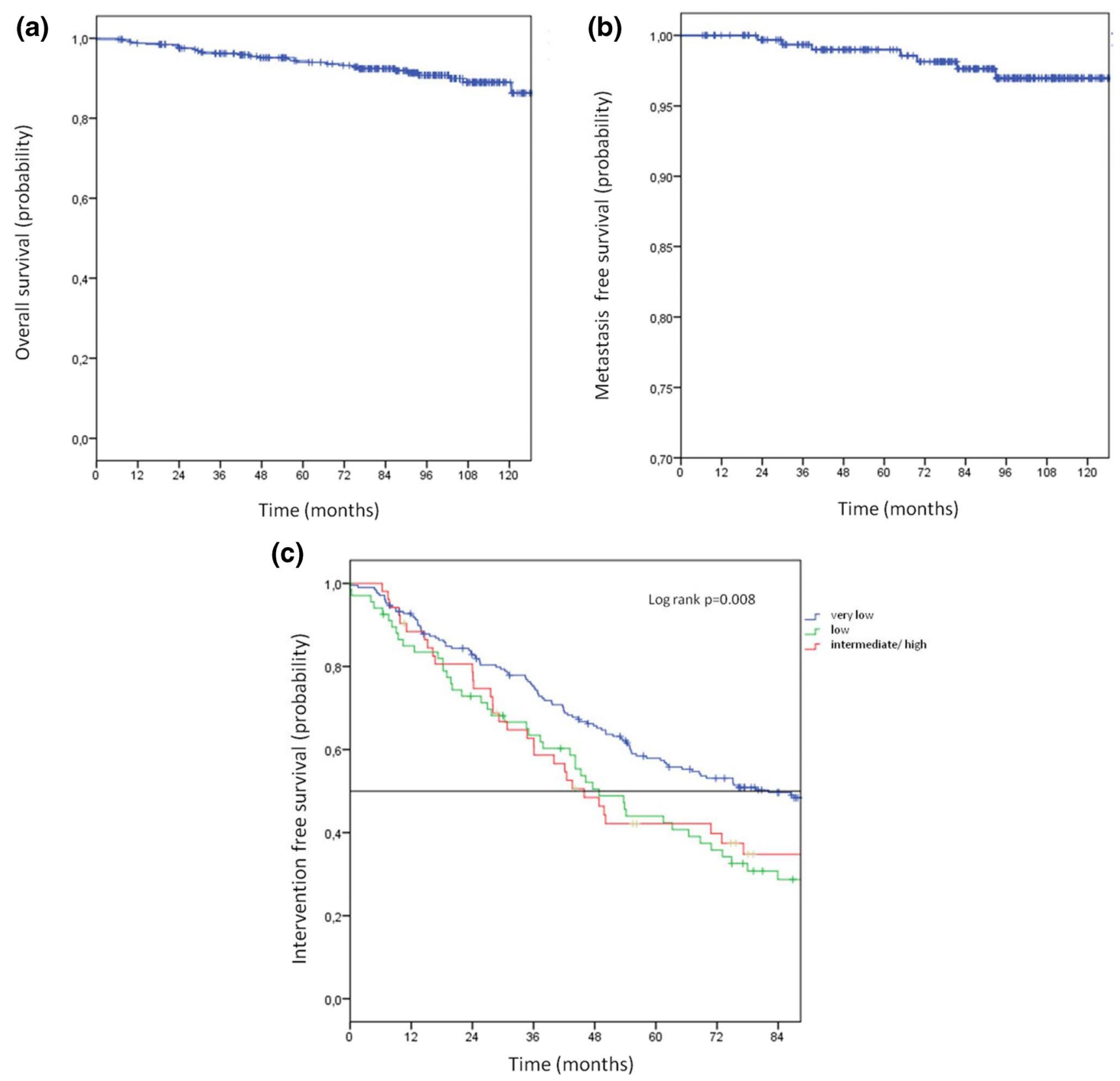

Fig. 2 Kaplan-Meier curves illustrating the a overall survival, $\mathbf{b}$ metastasis-free survival, and $\mathbf{c}$ the intervention-free survival stratified by risk groups for 329 active surveillance patients

AS, whereas additionally $15 \%$ switched from AS to WW and remained without invasive treatment.

With a median follow-up of 7.7 years, our cohort constitutes one of the very few studies that so far have reported intermediate to long-term outcomes of men managed with AS. A list of prospective cohorts reporting on AS outcomes is shown in Supplementary Table 3, demonstrating that nearly half of these are single-center studies from tertiary care centers $[3,4,7,15-20]$. The two most important single-center studies are from Sunnybrook Toronto and from Johns-Hopkins University, reporting on 15-year actuarial rates for cancer-specific survival of 94\% [3] and 99.9\% [7], respectively.

Of all multicenter-studies, the PRIAS-study is the one that probably best represents the real-life situation and is therefore closest to our study design [17]. This international AS study began in 2006 and included more than 100 centers in 17 countries worldwide with inclusions from academic, nonacademic, and private practices. ProtecT is the only study that compared RP, RT, and active monitoring, an adapted form of AS, in a prospective randomized setting with a 10-year follow-up. A significant difference between 
Table 2 Pathological findings in deferred radical prostatectomy after the termination of active surveillance for all three risk groups $(n=65)$

\begin{tabular}{lccccc}
\hline & Total $(n=65)$ & $\begin{array}{l}\text { Very low risk } \\
(n=37)\end{array}$ & $\begin{array}{l}\text { Low risk } \\
(n=18)\end{array}$ & $\begin{array}{l}\text { Int./high risk } \\
(n=10)\end{array}$ & $p$ value \\
\hline T-Category & & & & & 0.60 \\
pT2a & 5 & 3 & 2 & 0 & \\
pT2b & 4 & 0 & 2 & 2 & \\
pT2c & 37 & 24 & 10 & 3 & 0.22 \\
$\geq$ pT3 & 8 & 6 & 2 & 0 & \\
n.a & 11 & 4 & 2 & 5 & \\
Gleason grade group & & & & & \\
1 & 19 & 11 & 7 & 1 & \\
2 & 24 & 14 & 6 & 4 & \\
3 & 10 & 8 & 1 & 1 & \\
$\geq 4$ & 3 & 2 & 3 & 0 & 4 \\
n.a & 9 & 2 & & & \\
\hline
\end{tabular}

n.a. not available
Table 3 Multivariate analysis for the association between baseline characteristics and deferred invasive treatment

\begin{tabular}{|c|c|c|c|}
\hline Category & Adjusted HR & $95 \% \mathrm{CI}$ & $p$ value \\
\hline \multicolumn{4}{|l|}{ Age } \\
\hline Continuos & 1.0 & $0.99-1.01$ & 0.949 \\
\hline \multicolumn{4}{|c|}{ Charlson comorbidity index } \\
\hline 0 & Reference & & \\
\hline 1 & 1.78 & $0.98-3.21$ & 0.055 \\
\hline$\geq 2$ & 0.39 & $0.14-1.10$ & 0.073 \\
\hline \multicolumn{4}{|l|}{ PSA } \\
\hline$\leq 10 \mathrm{ng} / \mathrm{ml}$ & Reference & & \\
\hline$>10 \mathrm{ng} / \mathrm{ml}$ & 0.92 & $0.23-3.70$ & 0.9 \\
\hline \multicolumn{4}{|l|}{ PSA density } \\
\hline$<0.2 \mathrm{ng} / \mathrm{ml}^{2}$ & Reference & & \\
\hline$\geq 0.2 \mathrm{ng} / \mathrm{ml}^{2}$ & 2.55 & $1.49-4.36$ & 0.001 \\
\hline \multicolumn{4}{|c|}{ Gleason grade group } \\
\hline 1 & Reference & & \\
\hline 2 & 0.87 & $0.18-4.31$ & 0.871 \\
\hline \multicolumn{4}{|l|}{ cT-category } \\
\hline $\mathrm{cT} 1$ & Reference & & \\
\hline cT2 & 1.21 & $0.59-2.46$ & 0.607 \\
\hline \multicolumn{4}{|l|}{ Risk category } \\
\hline Very low & Reference & & \\
\hline Low & 0.56 & $0.16-1.91$ & 0.356 \\
\hline Interm./high & 1.05 & $0.44-2.50$ & 0.916 \\
\hline \multicolumn{4}{|c|}{ Number of positive biopsies } \\
\hline$\leq 1$ & Reference & & \\
\hline 2 & 1.37 & $0.85-2.21$ & 0.2 \\
\hline$\geq 3$ & 1.01 & $0.31-3.28$ & 0.984 \\
\hline
\end{tabular}

$H R$ hazard ratio, $C I$ confidence interval, $P S A$ prostate-specific antigen the treatment groups regarding survival rates was not found. However, disease progression and metastases occurred less frequently in patients who received RP or RT [4].

Some of our findings were noteworthy. First, regarding overall, cancer-specific, and metastasis-free survival our results are in line with all other AS-series revealing the same promising results. However, the cancer-specific survival in our study is $100 \%$ and therefore slightly higher compared to most other AS-series with medium- to long-term follow-up, reporting 1-2\% PCa death. Thus, it could be assumed that some PCa-specific deaths may not have been identified. To scrutinize this point, all treating urologists of the deceased patients were contacted. In 19/28 patients' causes of death could be determined, revealing no PCa-specific deaths. Furthermore, in none of the remaining nine patients an event of metastasis has been reported, so that even in these patients death of PCa seems to be unlikely (Supplementary Table 1).

Second, our intervention-free-survival of $37.4 \%$, including $22.2 \%$ under AS and $15.2 \%$ under WW, was lower compared to most other series, revealing intervention-free survival rates between 47 and $63 \%$ after 10 years. Interestingly, our results are close to that of the PRIAS-study, where 27\% of men adhered to AS, and 15\% switched to WW (or died of another cause) after 10 years of follow-up. In this regard, Hemelrijck et al. recently reported about discontinuation rates from a worldwide AS-database including 21 Centers in 12 countries, in which $39 \%$ of the patients were still on AS or WW after 10 years [21].

The observation of increasing discontinuation rates with an increasing number of study-centers may be an indication that switching to invasive therapy is more common in the routine care setting than in clinical studies from academiccenters. One reason could be that patients and physicians outside the academic setting feel less confident in dealing with AS. This becomes evident when examining the reasons 
for discontinuation: in HAROW 16.6\% discontinued without biopsy or PSA-progression due to patient wish or physician's advice. Likewise, in PRIAS 5\% discontinued due to anxiety or patient request, and $12 \%$ discontinued for other reasons without having a re-classification [17]. In contrast, in the Toronto-series only $6 \%$ discontinued upon patient preference without signs of progression [3].

This uncertainty, primarily affecting patients with higher risk features is reflected in our observation that low- and intermediate/high-risk patients discontinued AS much earlier than very low-risk patients (Fig. 2c). In this context, we were able to demonstrate in a previous investigation of our cohort, that the main reason for intervention in the intermediate-/high-risk group was patient preference without sings of progression [22].

Third, we demonstrated that the preference for invasive deferred treatment decreased with time. This indicates that in older age also HT and WW become part of AS. For a patient who initially selected AS and is no longer a candidate for invasive therapy due to increasing age or emerging comorbidities, the transition from AS to WW becomes an obvious option. On the basis of the Swedish national healthcare register, van Hemelrijk et al. estimated that $48 \%$ of men that started AS with a very-low-risk PCa change to WW after a median of eight years [23]. In this context, we could demonstrate in our cohort that patients switching to WW were significantly older than patients who remained in AS or opted for invasive therapy (Table 1).

Fourth, although re-biopsies and PSA measurements were only determined within the time of recruitment (2008-2013), it could be shown that follow-up examinations were fewer than expected: only $55 \%$ received at least one re-biopsy, and $71 \%$ received $\geq 4$ repeat PSA tests within this period. Similar observations of less intense follow-up outside controlled clinical trials could be demonstrated by Loeb et al. on the basis of a Surveillance, Epidemiology, and End Results (SEER)-Medicare database analysis. Among 5192 AS patients $>80 \%$ had more than one PSA test per year but $<13 \%$ received biopsy beyond the first 2 years [24]. However, at least in our cohort, the reduced follow-up studies do not seem to have any impact on the oncologic outcome.

Finally, on the multivariable analysis we could identify PSA-density $\geq 0.2 \mathrm{ng} / \mathrm{ml}^{2}$ as a predictor for receiving invasive treatment. This confirms the results of other AS-series, in which PSA-density was positively associated with the risk of biopsy re-classification [7, 19, 25].

The strength of our study includes its prospective nature, its non-interventional design, the long follow-up period, and the high number of study-centers, consisting mainly of office-based urologists, thus reflecting the reality of everyday conditions better than results of prospective AS studies from single tertiary-care centers.
One limitation of our study is the relatively high dropout rate of $29.7 \%$. Considering this rate more closely, it becomes evident that in nearly one-third of these cases the reasons for drop-out could be stated and only $20 \%$ were lost to follow-up, which is in line with other health care studies [26]. Noteworthy, in PRIAS only 107 of 5302 patients were followed for more than 7.5 years and even the prospective randomized ProtecT-trial report about $14 \%$ lost to follow-up [4, 17]. Further limitations include the lacking information about histologic results after RP or re-biopsy, as well as the frequency of follow-up examinations beyond the study period of 2008-2013. It should also be noted that our study was conducted in the era before mpMRI became available as diagnostic tools which since have shown promising results in better patient selection and monitoring for men who undergo AS [27]. Today, the use of mpMRI at baseline and for the assessment during surveillance is recommended by most guidelines [1,2], since the incorporation of mpMRI appears to be cost-effective, improves patient selection, and may reduce the necessity biopsies in the course of follow-up [28-30].

\section{Conclusion}

Our results demonstrate that $\mathrm{AS}$ is a safe treatment option for localized PCa within the real-life healthcare situation, outside of controlled trials which investigate pre-selected study participants and a set treatment protocol. We hope that this might encourage office-based urologists in particular regarding the implementation of AS and to counteract possible concerns against this treatment option. On the other hand, our results indicate that discontinuation rates are higher in the routine-care setting and more likely due to reasons other than re-classification on biopsy or PSA rise. In the future, it will be necessary to identify reasons for the prevailing uncertainty in dealing with AS and to further improve diagnostic tools to allow more patients without a progressive disease to pursue a non-invasive approach.

Author contributions JH project development, data analysis, manuscript writing. AS data collection, management, and analysis. TW data collection. UB data collection. AH manuscript editing. LW project development, data analysis, manuscript editing.

Funding Open Access funding enabled and organized by Projekt DEAL. The HAROW study was initiated and conducted by the Men's Health Foundation, Berlin, Germany, and financially supported by Gazprom Germania with an unconditional grant for data collection and data management. 


\section{Compliance with ethical standards}

Conflict of interest Jan Herden, Andreas Schwarte, Thorsten Werner, Uwe Behrendt and Axel Heidenreich declare that they have no conflict of interest. Lothar Weissbach has acted as a paid consultant for the Scientific Institute (WIdO) of the statutory AOK health insurance provider. He has received study support (third-party funding) from Gazprom Germania.

Ethics approval The HAROW study was approved by the ethics committee of the Bavarian State Board of Physicians (Nr. 08012). It was registered under study ID 479 at the DKSR (German Cancer Study Registry; February 2008). All procedures performed in the trial involving human participants were in accordance with the 1964 Helsinki Declaration and its later amendments.

Consent to participate Informed consent to participate was obtained from all individual participants included in the study.

Open Access This article is licensed under a Creative Commons Attribution 4.0 International License, which permits use, sharing, adaptation, distribution and reproduction in any medium or format, as long as you give appropriate credit to the original author(s) and the source, provide a link to the Creative Commons licence, and indicate if changes were made. The images or other third party material in this article are included in the article's Creative Commons licence, unless indicated otherwise in a credit line to the material. If material is not included in the article's Creative Commons licence and your intended use is not permitted by statutory regulation or exceeds the permitted use, you will need to obtain permission directly from the copyright holder. To view a copy of this licence, visit http://creativecommons.org/licenses/by/4.0/.

\section{References}

1. Mottet N, Bellmunt J, Bolla M et al (2017) EAU-ESTRO-SIOG guidelines on prostate cancer. Part 1: screening, diagnosis, and local treatment with curative intent. EurUrol 71:618-629

2. Mohler JL, Antonarakis ES, Armstrong AJ et al (2019) Prostate cancer, version 2.2019, NCCN clinical practice guidelines in oncology. J NatlComprCancNetw 17:479-505

3. Klotz L, Vesprini D, Sethukavalan P et al (2015) Long-term follow-up of a large active surveillance cohort of patients with prostate cancer. J Clin Oncol 33:2727

4. Hamdy FC, Donovan JL, Lane JA et al (2016) 10-year outcomes after monitoring, surgery, or radiotherapy for localized prostate cancer. N Engl J Med 375:1415-1424

5. Komisarenko M, Martin LJ, Finelli A (2018) Active surveillance review: contemporary selection criteria, follow-up, compliance and outcomes. TranslAndrolUrol 7:243-255

6. Thomsen FB, Røder MA, Jakobsen H et al (2019) Active surveillance versus radical prostatectomy in favorable-risk localized prostate cancer. Clin Genitourin Cancer 17:e814-e821

7. Tosoian JJ, Mamawala M, Epstein JI et al (2020) Active surveillance of grade group 1 prostate cancer: long-term outcomes from a large prospective cohort. EurUrol S0302-2838(19):30961-30963

8. Thomsen FB, Brasso K, Klotz LH, Røder MA, Berg KD, Iversen P (2014) Active surveillance for clinically localized prostate cancer-a systematic review. J SurgOncol 109:830-835

9. Weissbach L, Stuerzebecher S, Mumperow E, Klotz T, Schnell D (2016) HAROW: the first comprehensive prospective observational study comparing treatment options in localized prostate cancer. World J Urol 34:641-647
10. Herden J, Ansmann L, Ernstmann N, Schnell D, Weissbach L (2016) The treatment of localized prostate cancer in everyday practice in Germany. DtschArztebl Int 113:329-336

11. Heidenreich A, Aus G, Bolla M et al (2008) EAU guidelines on prostate cancer. EurUrol 53:68-80

12. Choo R, Klotz L, Danjoux C et al (2002) Feasibility study: watchful waiting for localized low to intermediate grade prostate carcinoma with selective delayed intervention based on prostate specific antigen, histological and/or clinical progression. J Urol 167:1664-1669

13. van den Bergh RC, Roemeling S, Roobol MJ, Roobol W, Schröder FH, Bangma CH (2007) Prospective validation of active surveillance in prostate cancer: the PRIAS study. EurUrol 52:1560-1563

14. Herden J, Weissbach L (2018) Utilization of active surveillance and watchful waiting for localized prostate cancer in the daily practice. World J Urol 36:383-391

15. Soloway MS, Soloway CT, Eldefrawy A, Acosta K, Kava B, Manoharan M (2010) Careful selection and close monitoring of low-risk prostate cancer patients on active surveillance minimizes the need for treatment. EurUrol 58:831-835

16. Selvadurai ED, Singhera M, Thomas K et al (2013) Mediumterm outcomes of active surveillance for localised prostate cancer. EurUrol 64:981-987

17. Bokhorst LP, Valdagni R, Rannikko A et al (2016) A decade of active surveillance in the PRIAS study: an update and evaluation of the criteria used to recommend a switch to active treatment. EurUrol 70:954-960

18. Godtman RA, Holmberg E, Khatami A, Pihl CG, Stranne J, Hugosson J (2016) Long-term results of active surveillance in the Göteborg randomized, population-based prostate cancer screening trial. EurUrol 70:760-766

19. Newcomb LF, Thompson IM Jr, Boyer HD et al (2016) Outcomes of active surveillance for clinically localized prostate cancer in the prospective, multi-institutional canary PASS cohort. J Urol 195:313-320

20. Thomsen FB, Jakobsen H, Langkilde NC et al (2019) Active surveillance for localized prostate cancer: nationwide observational study. J Urol 201:520-527

21. Van Hemelrijck M, Ji X, Helleman J et al (2019) Reasons for discontinuing active surveillance: assessment of 21 centres in 12 countries in the Movember GAP3 consortium. EurUrol 75:523-531

22. Herden J, Heidenreich A, Weissbach L (2017) Risk stratification: a tool to predict the course of active surveillance for localized prostate cancer? BJU Int 120:212-218

23. Van Hemelrijck M, Garmo H, Lindhagen L, Bratt O, Stattin P, Adolfsson J (2017) Quantifying the transition from active surveillance to watchful waiting among men with very low-risk prostate cancer. EurUrol 72:534-541

24. Loeb S, Walter D, Curnyn C, Gold HT, Lepor H, Makarov DV (2016) How active is active surveillance? Intensity of follow-up during active surveillance for prostate cancer in the United States. J Urol 196:721-726

25. Welty CJ, Cowan JE, Nguyen $\mathrm{H}$ et al (2015) Extended follow up and risk factors for disease reclassification in a large active surveillance cohort for localized prostate cancer. J Urol 193:807-811

26. Baunacke M, Schmidt ML, Groeben C et al (2020) Decision regret after radical prostatectomy does not depend on surgical approach: 6-year follow up of a large German cohort undergoing routine care. J Urol 203:554-561

27. Glass AS, Dall'Era MA (2019) Use of multiparametric magnetic resonance imaging in prostate cancer active surveillance. BJU Int 124:730-737

28. Sathianathen NJ, Konety BR, Alarid-Escudero F, Lawrentschuk N, Bolton DM, Kuntz KM (2019) Cost-effectiveness analysis of 
active surveillance strategies for men with low-risk prostate cancer. EurUrol 75:910-917

29. Glaser ZA, Porter KK, Thomas JV, Gordetsky JB, Rais-Bahrami $S$ (2018) MRI findings guiding selection of active surveillance for prostate cancer: a review of emerging evidence. TranslAndrolUrol 7:S411-S419

30. Stavrinides V, Giganti F, Trock B, Punwani S, Allen C, Kirkham A, Freeman A, Haider A, Ball R, McCartan N, Whitaker H, Orczyk C, Emberton M, Moore CM (2020) Five-year outcomes of magnetic resonance imaging-based active surveillance for prostate cancer: a large cohort study. EurUrol 78:443-451

Publisher's Note Springer Nature remains neutral with regard to jurisdictional claims in published maps and institutional affiliations. 